\title{
Privacy, dignity, and confidentiality: interview study with structured questionnaire
}

George Rylance

Respect for patients' privacy and dignity and the maintenance of confidentiality are long established principles of medical practice. The General Medical Council has emphasised that treating patients and families politely is important in establishing and maintaining their trust. ${ }^{2}$ Recent technological advances have changed the focus of privacy and confidentiality issues towards patients' identities in publications ${ }^{2}$ and security of medical records. ${ }^{3}$ Considerations of patients' dignity have concentrated on specific groups-for example, patients who are dying. ${ }^{4}$ Long established ideals and principles relating to privacy, dignity, and confidentiality, however, may not be expressed in clinical practice. As children and their parents have the same rights to these principles as adult patients, I conducted a survey of parents' views on these issues in the context of paediatric hospital practice.

\section{Subjects, methods, and results}

Using a structured questionnaire, I interviewed the parents (one parent (232 cases) or both together (68 cases)) of 300 child inpatients about privacy, dignity, and confidentiality experienced during their child's stay in hospital. The parents of children aged 3 months to 16 years who had been in hospital for at least 36 hours were non-selectively and opportunistically surveyed during visits to the hospital from May 1996 to October 1997. Interviews took place in the hospital during the child's stay or in the outpatient department within 4 weeks of discharge (234 and 56 children respectively). The children (of whom 90\% were aged $\leqslant 5$ years) were from three medical wards comprising bays with at least 4 beds (120 children), rooms with two beds (120), and single rooms (60).

The table shows the responses to the questionnaire. More than four fifths of parents reported overhearing confidential information on three or more topics that they would not have expected to hear through usual ward living or social contact (115 (96\%) parents of children in bays with $\geqslant 4$ beds; $106(88 \%)$ of those in twobed rooms; and none of those in single rooms). In $86 \%$ $(189 / 221)$ of cases, parents said that information was overheard from "ward rounds." The parents of the 282 children with medical conditions estimated that the number of people taking part in ward rounds was 1 to $8 ; 14$ parents of the 18 children with surgical conditions estimated that it was 15 or more.

\section{Comment}

The findings of this study-that dignity, privacy, and confidentiality were poorly respected on children's wards-are limited by several factors. Only three wards were used, although they accounted for the turnover of more than $60 \%$ of the hospital inpatients and involved more than 15 consultants. Memory may be variable and exaggerated, and overheard information could have resulted from close living and social contact on the wards. The aspects surveyed may not have been what parents consider to be important issues of privacy, dignity, and confidentiality. Also, children's views, which may differ from parents', were not elicited as few children were old enough to give a rational opinion. Some issues-for example, the desirability of curtain pulling-may be less important to them.

Ward rounds are identified as major problem areas. Their structure varied according to the consultant leading the round: some preferred a "business" round away from patients, followed by a bedside review; others conducted full discussion round the bedside. Although twice daily handover rounds were conducted away from patients, the other working arrangements and relatively large patient numbers seemed to predispose to traditional bedside rounds.

Maintaining confidentiality for children in single rooms suggests that ward design is important. Nevertheless, breaches of confidentiality and privacy, and lack of respect for patients' dignity, seem primarily to be problems of attitude, behaviour, and lack of thought.

If these results reflect patterns prevalent in paediatric practice then most children, parents, and carers receive care that falls far short of the General Medical Council's guidelines on good practice.

Contributors: GR is the sole contributor.

Funding: None.

Competing interests: None declared.

1 General Medical Council. Confidentiality and good medical practice. London: GMC, 1995.

2 Berry RM. The genetic revolution and the physician's duty of confidentiality. The role of the old Hippocratic virtues in the regulation of the new genetic intimacy.J Leg Med 1997;18:401-41.

3 Woodward B. The computer-based patient record and confidentiality N Engl J Med 1995;333:1419-22.

4 MacDonald WL. Situational factors and attitudes toward voluntary euthanasia. Soc Sci Med 1998;46:73-81

(Accepted 30 October 1998)

Number (percentage) of parents answering yes to questions relating to privacy, dignity, and confidentiality

\begin{tabular}{|c|c|c|c|c|}
\hline \multirow[b]{2}{*}{ Question } & \multicolumn{3}{|c|}{ Type of room child stayed in } & \multirow[b]{2}{*}{$\begin{array}{c}\text { Total } \\
(\mathrm{n}=300)\end{array}$} \\
\hline & $\begin{array}{l}\text { Bay with } \\
\geqslant 4 \text { beds } \\
(n=120)\end{array}$ & $\begin{array}{c}2 \text {-bed } \\
\text { room } \\
(n=120)\end{array}$ & $\begin{array}{l}\text { 1-bed } \\
\text { room } \\
(n=60)\end{array}$ & \\
\hline $\begin{array}{l}\text { Did you overhear (from hospital staff) conversations } \\
\text { giving personal information about other patients }\end{array}$ & $115(96)$ & $106(88)$ & NA & $221 / 240(92)$ \\
\hline
\end{tabular}
giving personal information about other patients and their families?^

How do you think you got the information?

\begin{tabular}{lcccc}
\hline From ward round? & $102(89)$ & $87(82)$ & & \\
\hline From staff conversation? & $13(11)$ & $19(18)$ & & \\
\hline Were people other than you (relative or friend) given & 48 & 59 & 23 & 130
\end{tabular}

Were people other than you (relative or friend) give
detailed information about your child's care or

condition?

\begin{tabular}{|c|c|c|c|c|}
\hline Were you asked permission for this in advance? & $22(46)$ & $30(51)$ & $15(65)$ & $67(52)$ \\
\hline $\begin{array}{l}\text { Did a doctor or nurse ever knock on the room door } \\
\text { before entering? }(n=180)\end{array}$ & NA & $10(8)$ & $13(22)$ & $23(13)$ \\
\hline Did a doctor or nurse ask if it was alright to come in? & NA & $3(3)$ & $6(10)$ & $9(5)$ \\
\hline $\begin{array}{l}\text { Did a doctor or nurse ever ask if you or your child } \\
\text { wanted curtain screening for examination }\end{array}$ & $48(40)$ & $60(50)$ & $8(13)$ & $116(39)$ \\
\hline
\end{tabular}
wanted curtain screening for examination

NA=not applicable.

*Information on 3 or more of the following: blood relationship of parents; chronic illness in family;

employment of parent; housing conditions; drug treatment; parentage; pregnancy; previous admission to

hospital; relationship disharmony; smoking habit; social drug use. 